\title{
Research on FDI Inflows and Economy Development of Jilin Province China
}

\author{
Lian Lina (Corresponding author) \\ School of Economics, Northwest University for Nationalities \\ PO box 730124 Lanzhou, P.R. China \\ Tel: +86-135-1963-0171Ｅ-mail: llnhappy2010@126.com
}

Hu Yuxia

School of Economics, Northwest University for Nationalities

PO box 730124 Lanzhou, P.R. China

Tel: +86-139-9315-8898Ｅ-mail: jkjkjk3723@yahoo.com.cn

Xu Jing

School of Economics, Northwest University for Nationalities

PO box 730124 Lanzhou, P.R. China

Tel: +86-136-1932-6667Ｅ-mail: bmcxj@126.com

Received: June 22, 2011 Accepted: August 2, 2011 doi:10.5430/jms.v2n3p42

\begin{abstract}
There is little doubt that the phase-in FDI is fuelling much of the rapid economic leap of China. Business leaders, government officials and academics are focusing considerable attention on the concept of the contribution of FDI inflows to the economic advancement in the host country China particularly in the realm of GDP furor. They are inclined to assume it as a matter of course that FDI injection in Jilin province is definitely one of the stimulating forces to its economy development. This article address this question through the lens of economics as to whether the FDI inflows to Jilin province is in complete compliance with its economic development on a sustainable basis, and whether such money injections further facilitate their impacts transfusing at best. The author synthesizes that FDI may have not crowded out domestic investment, but have been a complementary relationship with domestic investment, which has partly exerted positive powers on economic growth of Jilin province.
\end{abstract}

Keywords: FDI Inflows, Economy Development, Agglomeration Effects

\section{Introduction}

The financial crisis of 2008 led to a revaluation of the world power and the development benefits from a degree of openness to FDI. As supported by some empirical studies, it is possible that both FDI and economic growth are independent and could lead to two-way causality. On one hand, FDI inflows may promote economic growth of the host country through positive direct effects and spillover effects. On the other hand, countries with rapid economic growth can provide better opportunities to attract greater volume of FDI, as well as generate more demand for FDI. Therefore, through the use of FDI, developing countries not only can alleviate the shortage of domestic savings and foreign exchanges, but can promote the capital accumulation and economic growth. There is little doubt that FDI has contributed significantly to Chinese economic development, yet the story is not quite as rosy as these summary sentences outlined. Many anecdotal evidences suggest that despite the capital under-dispersion from the axis powers of donators, the sector and geographic distribution of the FDI is quite uneven with eastern China in a high conjunction with the foreign inhabitants with Guangdong, Jiangsu, Fujian and Shanghai in descending order strengthened by Zhejiang, Beijing, Tianjin and north-east industrial zone of China while the residual majority even immediately adjacent to the coastal areas are slightly touched. This will definitely be a stimulating force to the economy disequilibrium.

Jilin province is located in north-east China. Three advantages have made it one of the historically-renowned industrial 
bases. First is the industry advantage with the manufactured industry as the core part of the domestic economy and accounting nearly $50 \%$ of the total industry output, say, the petrochemical industry, bio-pharmaceutical industry, hi-tech industry, supplemented by metallurgy, construction materials, tourism etc. Changchun FAW-Sihuan Automobile Co. Ltd, with highly matured R\& D capacity and production potentiality, is the biggest production base of rail vehicles in Asia. In 2009, the market share of rail cars took up half of the total of China, and 85\% in its underground railcars. Second is agriculture and this owes greatly to its geographic location, say, black soil and the endowed location in the global corn belt have made Jilin province the grain production base and the important place for stock economy as well. Jilin province tops the list in the corn exportation as compared with other provinces in China and has cultivated many well-established companies in processing of beef, corn and chicken for the Asian market. The third is talent advantage with 42 renowned colleges and universities, 209 R\& D institutions, 8 major state labs, thus making Jilin province one of the forerunners in optics, applied chemistry, genetic engineering and auto industry etc. Based on the relevant research papers, we may draw a conclusion that Jilin province, though natured through centuries, is comparatively strong in agricultural development yet rather weak in industrialized economy. How to gender the economic development at a higher rate becomes quite important, but this may be confined to the central issue as the appropriate role of FDI inflow totally tailored to the local economy agenda. This study is focused on controversies surrounding the effects of FDI in the proposed collaborative relationship with the developing host countries in stimulating the economies as in the ways of promoting market integration, diversifying market supplies, and exercising as strong backbones for the money injections of the economy appetites. The first section of the study encompasses an introduction to the FDI in Jilin province. Section two outlines the cohesions of paid-in FDI, domestic investment and economy development as exemplified by the affirmative data. Section three summarizes the findings and sketches some reflections about concrete actions to further the spread of FDI in properly arranged strategies.

\section{Literature Review}

The turn of the new century seemed to spark the rapid buildup of Foreign Direct Investment in China during which China ranked the eighth in FDI inflows and leaped to the forth host country in 2006 only behind the United States, the United Kingdom and France, then the fifth in 2007 eclipsed Canada, and in 2009, ranked the second as the FDI recipient just following the United States. The grown importance of China onto the world stage has spawned a proliferation of research papers written on the various aspects of China's inward FDI. The varying impact of country-, industry-, and firm-specific considerations on the location characteristics of countries has been extensively analyzed by the international economists as Dunning and Gray in as early as 1982. Most of the research papers are, from differentiated perspectives, sketching the positive effects of FDI inflows on Chinese economy leaps. The Savings Shortage theory by Rosenstein and Foreign Exchange shortage theory by Mckinnon and Balassa, as later in 1960s the developed Double Shortages theory by Chenery, $\mathrm{H}$ and Stront, A,M are theoretical foundations of driving forces of FDI inflows to the economic leap of developing host countries, as which may exercise as strong backbones for the money injections of the economy appetites, thus acquire a kind of collaborative relationship with the recipient countries as in the ways of promoting market integration, diversifying market supplies, and fueling technological and management spill-over etc. Many Chinese scholars launched researches since 1990s as to the positive effects of FDI inflows on domestic economic development. Chen guohong and Zheng zhaolian conclude that FDI inflow is the crux driver for the technological spur of China by utilizing co-integration analysis on the statistical data from 1981. Using the statistical data from 1987 to 1998 on the 29 Chinese provinces and cities, Shenkunrong and Gengqiang formulate a inner-derived model in their thesis and confine the findings that FDI inflow is both an undeniable incentive to economic development rate, and an indispensable lure to technology spill-over and human capital turnover. Xiao zheng and Shen yan figures out that there exists definite interaction between FDI inflows and economy development, or as the other case may be. Similarly, Wei houkai, Yang liuyong and Yang haiyan are trying to make assessment as to the FDI inflows and the economic advancement of one chosen province in the chosen time-span.

Until recent years, a limited profile is evident in the literatures on the uncrowned perils of FDI inflows from several buzz word of some Chinese scholars with a long list of Huang Jianjun (2001), Wang peizhi(2003), Wang Suqin (2005), many others in 2006 as Zhang wang, Jing Yuqin, Wu jun, Shu qin, and Si yong in 2007 sparks their eagerness in their essays in aspects of national security, FDI threats on the domestic industries development, the national treat toward foreign affiliates, and doubts on technology dispersion and so on. Wu sanmang, in his 2008 doctoral dissertation declares clearly the U-shaped province cell of China, and the regional gap between east and west area are primary contributor of regional disparity, yet FDI affects regional economic gap and cement the imbalance between.

As compared to this, the literature researches on FDI in northeast of China or specifically on Jilin province remain nil in the international arena and rather sparse in the domestic sphere. Liu dan in his research paper Co-integration Analysis of FDI and Economic Development of Jilin Province confines the findings that FDI is a stimulating force of economic 
advancement, yet the latter is not the direct lure of FDI furor of recent years. Similarly, Yu xiaolin touches the question in her dissertation. Based on the theoretical and empirical study, the author founds the import is a crystal-clear force of economic development, yet no-causality linkage between either export or FDI and economic advancement. In 2007, Zhao yinghui and Xiu chunliang attempt to examine the investment benefits of eight cities of Jilin province by constructing an evaluation index system with three key standards as economic growth, social development and environment cohesion and twenty exemplifying sub-standards. They sum up that the central region of Jilin province enjoys a comparatively most favorable investment environment followed by the eastern section and western the least. Yin zhenjie, in the same year expounds the relationship between FDI and employment in Jilin province as the co-related coefficient is $1 \%$ to $0.46 \%$. Xie haijun, in his thesis of March, 2008, utilizing co-integration analysis and Granger-causality test demonstrates the fact that a long-term balanced relations exist between the FDI and agricultural economic growth in northeast areas and that FDI is propitious to agricultural growth yet not so remarkable. Li wanhong and Lianghe, effect a detailed appraisal of the FDI environmental factors of three provinces of northeast China including Liaoning, Heilongjiang and Jilin. Their findings are conductive as that Liaoning is the most preferred target area of the three for its optimal combination of infrastructure projects, political climate, culture openness and economic potentiality, while Jilin ranks the second and Heilongjiang least preferred for varied outlets to enhance their charms for FDI injection. Li jie, in his MBA dissertation of 2009 expatiates an in-depth analysis of the casual relations between FDI and import\& export of Jilin province by use of unit root test, co-integration test, error correction and Granger causality test. The Empirical Analysis on the Effect of FDI in Jilin Province of November 2010, Zhang weiwei and Liu lizhen sketch the key issues through regression analysis and factor analysis, they show their concerns that among the composite factors market size expansion and lower cost are rather important while lower degree of economic openness and unstable energy supply are the constraints of FDI inflows of Jilin province.

The general literature review discloses that the scholars or practitioners have realized the importance of FDI injection and usually allege it as one of the indispensable stimulating factors for the economy development, employment, import\& export, or even go farther as to the industrial zoning or the process of globalization of Jilin province. They are managing to pinpoint the push-degree as numerable as to figure out the constructive countermeasures to outweigh FDI in the approaching future. Yet it is beyond the reach of all the scholars to come to consensus as from different perspectives of study. This is an open question and the key question of the paper that whether the quantitative effects of FDI inflows to economic growth of Jilin province are dramatic or not. With respect to the correlations of domestic investment in fixed assets, paid-in FDI and GDP growth, the paper has a comparatively less explanatory power as to which of the former two factors is more contributable to the GDP growth of Jilin province.

\section{Panorama of FDI Inflows in Jilin Province}

For quite a long time period, how to make the domestic investment climate hospitable enough to attract FDI inflows to feed the economy development is the crux of the government and firms of Jilin province. Since economic growth is the most important determinant of the ability to attract FDI, the FDI inflows whether further accentuated by the financial crisis is always the signal of key markets attractiveness and thus a rivet to soften the decline as far as possible.

\subsection{Scale of FDI Inflows}

The time span before the year 1990 is always considered as the initial stage of FDI inflows to Jilin province with the slowly ascending amount and the small share of FDI in the total GDP.

\section{<Table 1 about here>}

As shown by table one, though the data of the actual paid-in FDI in 1998 is missing for the crushing Asia financial crisis, it is still quite obvious that after that of the turning-point 1990, the actual paid-in FDI injection in Jilin province is increasing steadily and nearly climbs up to 50 times of the former stage till 2006. Especially in recent years, with the sponsorship of the series of policies to revitalize the Northeastern Old Industrial Base of China, the government of Jilin province employs numerous measures to attract FDI inflows and sprouts attainments thereafter, say, in 2007 the actual paid-in FDI totals US\$2.271 billion with a 27\% increase as compared with the previous academic year, and in 2008 US $\$ 3.008$ billion with $24.5 \%$ increase, in 2009 it is US\$3.567 billion and in 2010, the paid-in FDI of Jilin province hit its peak of US\$4.165 billion.

\subsection{Source of FDI injections}

On account of the disaggregated data from 1982 to 2006, it is extremely obvious that the sources of FDI inflow to Jilin province is overwhelmingly concentrated, with Hongkong, the British Virgin Islands, Germany, the Republic of Korea and U.S the main capital donators. This statement may be exemplified by the name list of the fifteen core countries or regions of FDI injections from 1982 to 2006, the aforesaid five countries occupying a high proportion of 72.54\% in total, 
with $27.4 \%, 16.89 \%, 11.49 \%, 8.92 \%$, and $7.84 \%$ respectively in descending order. We may argue that Hongkong, a largely self-governing "special autonomous region” of China itself, whilst its number one dominance is somewhat illusory in that much FDI normally from Hongkong yet in reality from elsewhere with some Hongkong-source FDI in fact funded by domestic Chinese that is round-tripped through Hongkong and others from various western countries, say, some U.S. or Japanese firms place their target investment to mainland China via subsidiaries in Hongkong. This sounds feeble to reset another resonance of divergence.

\subsection{Target Sectors of FDI Inflows}

The FDI inflows of Jilin province cover wide ranges with the crux mission of sponsoring the equipment manufacturing of the secondary industry, which has been deemed typical for inward FDI zoning of Jilin province, whilst less funding of the primary and tertiary industry. The statistic data from 1997 to 2006 shows explicitly that manufacturing sector is the traditional target industry of foreign investment which holds the largest and growing share of $78.1 \%$ in the total inward FDI of Jilin province. Simultaneously, paid-in FDI of services of all kinds accounts for a small fraction of 3.14\%.

\subsection{Concrete Ways of Inward FDI}

Three sources of FDI inflows are green field investment, merger\& acquisition and re-investment of retained earning. In developed economies, M\& As have been the dominant drivers of FDI inflows as during 1987 to 2007, on average, M\& As accounted for more than $70 \%$ of the developed countries' FDI inflows. The reverse is definitely true with green field investment and retained earnings the dominant sources of FDI inflows in developing economies. Green field investment in the concrete form of wholly-owned foreign affiliates is overwhelmingly prevailing in the FDI inflows of Jilin province. The statistic data of 2006 reinforced the statement as the wholly-owned foreign affiliates took up 55.33\% of the total inward FDI. It is impossible to precisely predict how the various factors had played out for this trend. They need to be seen against the long-term nature of FDI, undertaken in line with boarder corporate strategies, which makes green field type of FDI more stable than M\& As and hence could mitigate some of the immediate negative effects.

\section{Agglomeration Effects of FDI Inflows on the Economy Development of Jilin Province}

Based on the database from yearbooks of the Statistical Report of the National Economy and Social development in Jilin Province from 1984 to 2010, we make figue one with three variables of GDP growth, investment in fixed assets and paid-in FDI. As the GDP growth, investment in fixed assets are shown in RMB yen while the paid-in FDI is all the time being outlined in US dollars, the exchange has been effected with the year 1994 chosen as the base period since it is considered as the turning point of the exchange rate revolution in China and the market-oriented philosophy was generated since then. Another reason for doing so is the year 1994 may be seen as nearly the mid-year in the sample time period. The exchange rate therein was 8.7 US dollars via RMB yen. We do not deny one fact that the chart can not show exactly the tendency of the three variables, for anyway there exists huge difference as in the exchange rate of US dollar and RMB yen as being evidenced that in the year 1984 it was averaged 2.30, 8.70 in 1994 and 6.50 in the year 2010.

\section{$<$ Figure 1 about here $>$}

From figure one, it is rather obvious that before the year 1990, the linear trends of the GDP growth, investment in fixed assets and the paid-in FDI are overlapping to such extent that one can not define them respectively. After that, the GDP growth seems to execute a steep soar-up for several years and develop steadily then shows economy flies from the year 2001. Simultaneously, the investment in domestic fixed assets and the paid-in FDI develop at the similar pace, and from the year 2005 both obtain a quick growth, and the investment in domestic fixed assets appears the acquire an even higher rate of development and eclipses the GDP growth in the year 2010.

The Endogenous Growth Theory, introduced and developed by many western economists as Lucas, Schultz, Becker, Cass, Koopmans, Ramsey etc., has provided fresh perspectives of explanation to the economy advancement of a nation or a specific region. It announces explicitly that the economy of the host countries may prosper at a higher speed on the condition that the FDI inflows can, by any possible means, consolidate the capital accumulation of the host countries. This implies that the phase-in foreign capital shall not squeeze out the domestic capital injection, but may perform to the adverse, that is, the inward FDI may spur the size and density of the domestic investment. Consequently, under the dual powers, the economy should develop dramatically. The figure one tells us that during the chosen time span, the GDP growth, investment in fixed assets and the paid-in FDI are increasing, whist the domestic investment is arising at a higher pace than that of the paid-in FDI.

\section{Conclusion:}

Quantitative effects of FDI inflows to economic growth of Jilin province are dramatic to some extent. This finding means that FDI may have not crowded out domestic investment, but have been a complementary relationship with 
domestic investment, which has partly exerted positive powers on economic growth. This shall be concluded that even if within the territory of one nation, the impact of FDI varies between industries and regions, depending on region characteristics, labor force, and the policy environment. Since the FDI spillovers can not, in all probabilities, be easily disentangled from its economic cohesions, the government of Jilin province should conduct the FDI inflows as no more than a cosmetic exercise but strategically tailored to suit the domestic requirements of economic development.

\subsection{Utilize the Benefits of Inward FDI}

Theoretically, FDI in diversified forms of capital outflows or inflows is possible for either market-seeking or resource-seeking purpose. It is somewhat ominous that much of the foreign furor over foreign-controlled enterprises in China is an offshoot of rich raw materials, comparatively cheap labor force, and the great market potentiality alleged by the huge population. Jilin province, with the population of 27 million and RMB 12,829 per capita disposable income of urban households as shown by the statistic bureau by the end of 2008, is undeniable to lead the industrial corporation as thoroughly transnational in scope and impacts with its power arguably grown in giving a context of emerging consumer markets. This may be further reinforced by the sufficient labor force and comparatively lower salary level thus to entice an expanded worldwide search for cost-effective production and increasingly flexible marketing netting. All these advantages combine together to attract the US industrial zone to relocate in Jilin at the beginning of 2007, and will definitely be practical FDI incentives in the coming decades. The government officials of Jilin province should make the regional investment environment more acceptable to foreign firms from the upstream resource extraction to service delivery and a sound investment climate based on transparent and predictable regulatory and policy framework. The FDI inflows shall spur forward the economic development of Jilin province with the axis power of funding the traditional industries. At the same time, equal competing environment should be provided for FDI and domestic investment, to enhance the aggregate effects. It may be expected that the strategically utilized FDI inflows shall definitely support the local firms to move up the global value ladder and try to sink into fertile hi-tech industries.

\subsection{Cultivate competent labor force to match the global system}

The consolidated effect of FDI is definitely related to educational level of the work force of the host country, or as the case may be, the host region. Positive effects of FDI occur only when the host region has a minimum threshold level of proficient human capital, reinforced by increased technology diffusion and acquisition of product and process innovation and better management practice, which are all conductive to economic growth. So, it is rather strident to develop human resources to manage foreign affiliates and operate integrated international production networks. The government of Jilin province would better authorize a wide range of government-funded or organized consortia in research\& development and commercialization of advanced technologies. Meanwhile, the domestic firms may gain asymmetry position with those of MNCs, thus make innovative use of technologies and further acquiring the core know-hows possible.

\section{References}

Blomquist, Robert. (2006). "Six Thinking Hats for the Lorax: Corporate Responsibility and the Environment”. Georgetown International Environmental Law Review 18(4): 691-705

Government website of Jilin province 2010

Li wanhong and Lianghe, Appraisal and Comparison of the FDI Environmental Factors of Three Provinces of Northeast China, http://www.cnki.net (in Chinese)

Lijie, Research on Casual Relationship between FDI and Import\& Export of Jilin Province, http://www.cnki.net (in Chinese)

Liu dan, the Co-integration Analysis of FDI and Economic Development of Jilin Province, http://www.cnki.net (in Chinese)

Xie haijun, the Relationship between FDI Inflows and Agricultural Economy Growth in Northeast China, Journal of Dalian Nationalities University, Vol 110, No.2, March 2008 (in Chinese)

Zhao yinghui, Xiu chunliang, Research on Urban Investment Benefits Evaluation-From Perspectives of Eight Cities in Jilin Province, http://www.cnki.net (in Chinese) 
Table 1. GDP Growth and FDI Inflows of Jilin Province from 1984-2010. Measurement Unit: GDP Growth=RMB billion, Paid-in FDI=US\$ billion.

\begin{tabular}{|c|c|c|}
\hline year & GDP Growth & Paid-in FDI \\
\hline 1984 & 35.64 & 0.00215 \\
1985 & 42.22 & 0.00488 \\
1986 & 47.36 & 0.0258 \\
1987 & 27.22 & 0.0393 \\
1988 & 33.63 & 0.054 \\
1989 & 36.13 & 0.0337 \\
1990 & 39.39 & 0.0607 \\
1991 & 42.41 & 0.16 \\
1992 & 51.45 & 0.22 \\
1993 & 67.05 & 0.65 \\
1994 & 97.4 & 0.81 \\
1995 & 120.5 & 0.9 \\
1996 & 131.45 & 1 \\
1997 & 145.04 & 1 \\
1998 & 156.44 & 1 \\
1999 & 167.06 & 0.421 \\
2000 & 182 & 0.493 \\
2001 & 203.25 & 0.522 \\
2002 & 224.30 & 0.552 \\
2003 & 252.18 & 0.318 \\
2004 & 295.82 & 0.570 \\
2005 & 361.49 & 1.151 \\
2006 & 424.92 & 1.650 \\
2007 & 522.61 & 2.271 \\
2008 & 642.41 & 3.008 \\
2009 & 740.2 & 3.567 \\
2010 & 857.71 & 4.165 \\
\hline
\end{tabular}

Data Source: the Yearbook of the Statistical Report of the National Economy and Social development in Jilin Province 


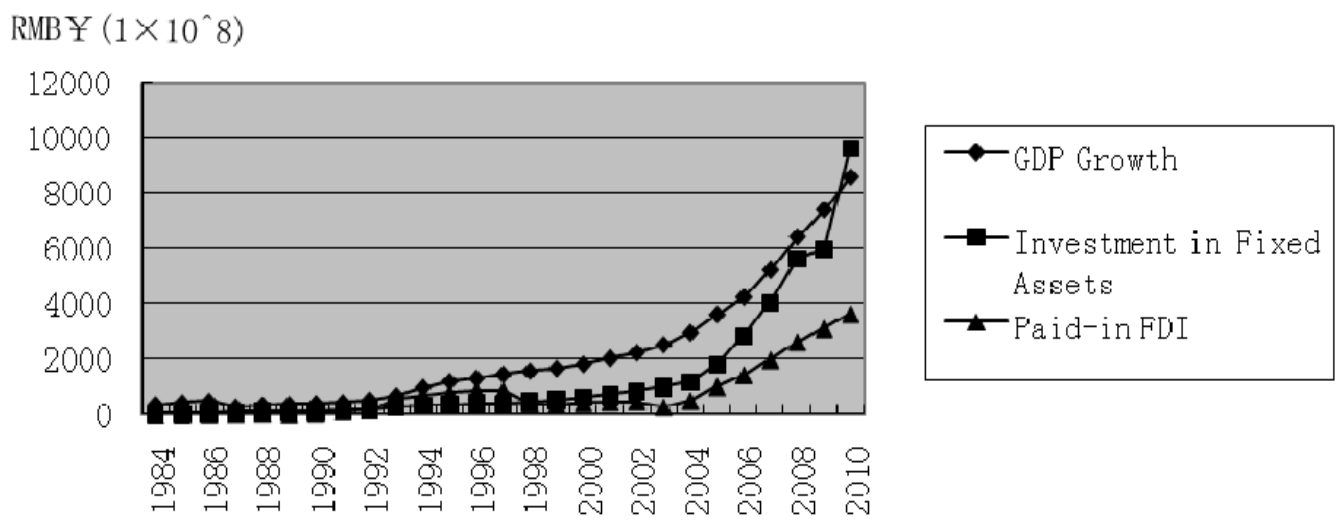

Figure 1. The GDP Growth, Investment in Fixed Assets and Paid-in FDI of Jilin Province from 1984-2010 